\title{
Lip-Licking Deer Shitting
}

\section{Meditations}

When you become such good friends with black-tailed deer

that live in the black oak forest

Sierra Foothills

That 20 feet away they graze contemplating you

as you sit on a stump in silence

admiring them

And they think nothing of shitting in front of you

looking over their shoulders

across their backs and rear-ends

their black tails lifted

As the perfectly-shaped same-size brown pellets fountain out

in a delicate continuous fountain,

And when they gaze at you

with their big black eyes

while they shit

And suddenly their long pink tongues curl out

and they're licking their lips,

Licking their lips while shitting

and looking over at you

with their deep shy eyes,

Isn't it proper etiquette to lick your lips back, to think nothing of pissing in front of them, showing off your cock and the long arc of urine saved up for them

knowing they like

its salty savor

like salad dressing

on their grass and mushrooms,

Isn't it proper etiquette you should look at them curious playful friendly

and lick your lips in return?

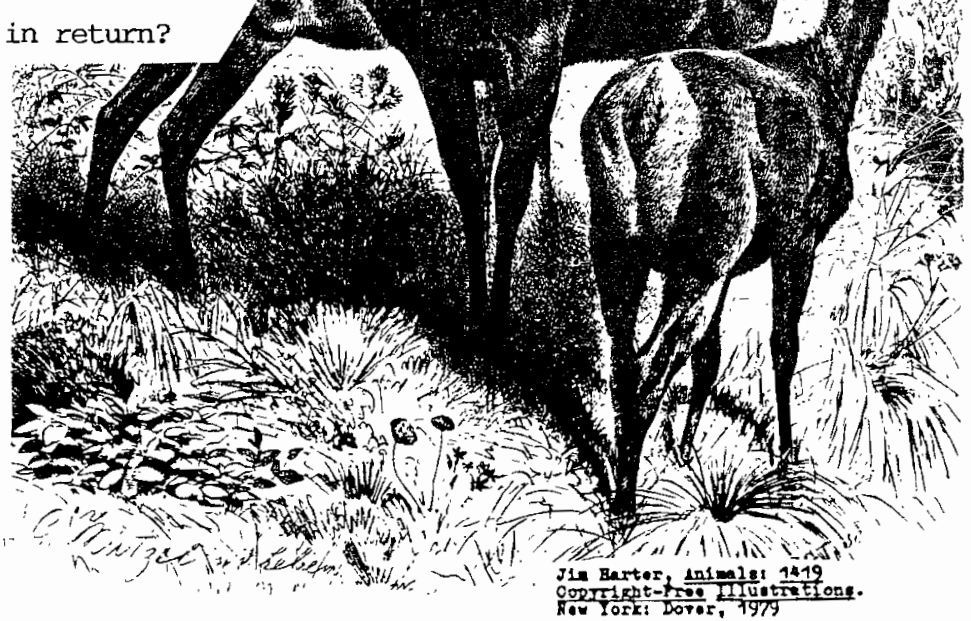

ANTLER 